\title{
Dipteran Carboxymethyl Chitosan as an Inexhaustible Derivative with a Potential Antiproliferative Activity in Hepatocellular Carcinoma Cells
}

\author{
Rana M. Abdel Rahman, ${ }^{1}$ Hedayat Abdel Ghaffar, ${ }^{2}$ Afrah F. Alkhuriji, ${ }^{3}$ \\ Mahmoud I. Khalil $\mathbb{D}^{4,5}$ Noha Amaly, ${ }^{6}$ Attalla F. El-Kott, ${ }^{1,7}$ and Ahmed S. Sultan $\mathbb{D}^{8}$ \\ ${ }^{1}$ Zoology Department, Faculty of Science, Damanhour University, Damanhour, Egypt \\ ${ }^{2}$ Zoology Department, Faculty of Science, Alexandria University, Alexandria, Egypt \\ ${ }^{3}$ Department of Zoology, College of Science, King Saud University, Riyadh, Saudi Arabia \\ ${ }^{4}$ Department of Biological Sciences, Faculty of Science, Beirut Arab University, Lebanon \\ ${ }^{5}$ Molecular Biology Unit, Zoology Department, Faculty of Science, Alexandria University, Alexandria, Egypt \\ ${ }^{6}$ Polymeric Materials Research Department, Advanced Technology and New Materials Research Institute (ATNMRI), \\ City of Scientific Research and Technological Applications (SRTA-City), Alexandria, Egypt \\ ${ }^{7}$ Biology Department, Faculty of Science, King Khalid University, Abha, Saudi Arabia \\ ${ }^{8}$ Biochemistry Department, Faculty of Science, Alexandria University, Alexandria, Egypt
}

Correspondence should be addressed to Mahmoud I. Khalil; m.khalil@bau.edu.lb and Ahmed S.Sultan; dr_asultan@alexu.edu.eg

Received 29 December 2019; Revised 26 August 2020; Accepted 4 September 2020; Published 28 September 2020

Academic Editor: Raffaele Capasso

Copyright ( $\odot 2020$ Rana M. Abdel Rahman et al. This is an open access article distributed under the Creative Commons Attribution License, which permits unrestricted use, distribution, and reproduction in any medium, provided the original work is properly cited.

\begin{abstract}
Traditional folk therapies indicate that insects have diverse medicinal potentials. However, the therapeutic application of insect chitosan and its derivatives has not been explored. To investigate the application of chitosan and its derivatives, the carboxymethyl derivative of chitosan (CM-Ch) was extracted from two dipteran larvae species, Chrysomya albiceps and Sarcophaga aegyptiaca. The degree of deacetylation (DD) and CM-Ch functional groups were validated using Fourier-transform infrared (FTIR) spectroscopy analysis and proton nuclear magnetic resonance spectroscopy $\left({ }^{1} \mathrm{H}\right.$ NMR), respectively. The molecular weight was estimated using MALDI-TOF MS analysis. The effect of CM-Ch on the morphology and proliferation of human liver HepG2 cancer cells was assessed. $\mathrm{IC}_{50}$ of CM-Ch induced significant growth-inhibitory effects in HepG2 cells. CM-Ch treatment altered the morphology of HepG2 in a dose-dependent manner and induced apoptosis in a caspase-dependent manner. CM-Ch treatment showed no signs of toxicity, and no alterations in liver and kidney biochemical markers were observed in albino rats. A CM-Ch derivative from commercial crustacean chitosan was used to assess the efficacy of the insect-derived CM-Ch. The data presented here introduce insect CM-Ch as a promising, inexhaustible, safe derivative of chitosan with antitumor potential in liver cancer. This is the first report highlighting the anticancer activity of insect CM-Ch in hepatocellular carcinoma cells.
\end{abstract}

\section{Introduction}

Primary liver cancer is a major public health problem that causes around half a million deaths per year worldwide. Moreover, the incidence of primary liver cancer is increasing. Hepatocellular carcinoma (HCC) is the most common primary liver cancer malignancy [1] and is one of the most predominant cancer types in Egypt [2]. Natural products and their derivatives have been recognized as essential therapeutic sources [3]. Historical and traditional folk therapies have revealed that insects present diverse biological activities and medicinal potentials. Investigating relatively unexplored habitats and novel organisms can maximize the success of drug discovery efforts. Indeed, very few insects have been screened for therapeutically relevant molecules [4]. 
Various substances extracted from insects, including chitin, antibacterial peptides, and polysaccharides, have been studied $[5,6]$. Chitin is widely distributed in the cuticles of crustaceans and insects and in the cell walls of some fungi and microorganisms [7]. Chitosan is the alkaline deacetylated derivative form of chitin [8]. The distinctive feature of commercially available crustacean raw chitin is it contains a large amount of other substances, including fatty acids, lipids, calcium phosphate, and carbonates. The commercial extraction of chitin from traditional resources constitutes a high natural environmental load that is restricted by season $[9,10]$. Owing to the enormous biodiversity of insects, more attention has been focused on the commercial preparation of chitin and chitosan from insects for applications on a wide biomedical scale $[6,11]$. Chitosan possesses biological characteristics including biocompatibility, nonimmunogenicity, antimicrobial activity, and biodegradability. Accordingly, chitosan has been used in food, biotechnology, and pharmaceutical industries as an antifungal, antibacterial, antitumor, immune-enhancing, anticholesteremic, and antithrombogenic agent and for the amelioration of diabetes and painful diabetic neuropathy [12-15]. Additionally, combining chitosan with other compounds is an efficient and safe adjuvant for the hepatitis $B$ vaccine in a mouse model [16]. Nevertheless, chitosan application is severely limited because it is insoluble in neutral or alkaline $\mathrm{pH}$ because of its stable crystalline structure, low absorbability, high molecular weight, and high viscosity [17]. Recently, carboxymethyl chitosan (CM-Ch) has received attention because of its solubility in water, biocompatibility, antibacterial and antitumor properties, and low toxicity $[8,18]$.

Chrysomya albiceps and Sarcophaga aegyptiaca are prevalent necrophagous species of medical importance worldwide. These species exhibit a broad worldwide distribution and are characterized by having a short life cycle, which is a major requirement for controlled laboratory rearing $[19,20]$.

This study was designed to investigate the potential of $\mathrm{CM}-\mathrm{Ch}$, as an insect extract, to be used as a biomedical approach for liver cancer therapy. To this end, we developed a cheap and commercially feasible chitosan extraction procedure from two unexplored dipterous insect sources, C. albiceps and S. aegyptiaca. We then systematically evaluated the potential anticancer activities of insect CM-Ch on the HepG2 human hepatocellular carcinoma cell line and performed a preliminarily investigation of the acute toxicity of CM-Ch in vivo.

\section{Materials and Methods}

2.1. Insect Collecting and Rearing. Prepupal stage C. albiceps and $S$. aegyptiaca were gathered from exposed rabbit carcasses at the botanical garden of the Faculty of Science, Moharrem Bey District, Alexandria, Egypt. The collected prepupae were transferred into a bowl containing dry autoclaved sawdust for pupation. Pupae were transferred to adult cages. Adult flies were maintained in rearing cages at room temperature. Each cage consisted of water, granular sucrose, powdered yeast, and powdered milk. Each cage was supplemented with a dish of $100 \mathrm{~g}$ of fresh beef liver that was removed once sufficient eggs were laid, in the case of C. albiceps, or sufficient larvae emerged, in the case of viviparous $S$. aegyptiaca. Newly hatched first instar larvae were transferred into $100 \mathrm{~mL}$ jars containing $50 \mathrm{~g}$ of cow liver. Each jar was placed in a larger beaker containing a $2 \mathrm{~cm}$ bed of dry sawdust and covered with a fine nylon mesh. Jars were kept at $25 \pm 2{ }^{\circ} \mathrm{C}$, in $60 \% \pm 10 \%$ humidity, and a photoperiod of $12 \mathrm{~h}: 12 \mathrm{~h}$. Third instar larvae were stored at $-20^{\circ} \mathrm{C}$ for chitosan extraction.

2.2. Chitosan Extraction. Chitosan was extracted from S. aegyptiaca and C. albiceps larvae as described previously [21] with some modifications. In brief, larvae were washed with $15 \%$ aqueous $\mathrm{NaCl}$ and dried at $50^{\circ} \mathrm{C}$. To retrieve crude chitin from the cuticle, larvae were treated with $1 \mathrm{~mol} / \mathrm{L}$ aqueous $\mathrm{NaOH}$ for $6 \mathrm{~h}$ at $100^{\circ} \mathrm{C}$. The retrieved crude chitin was rinsed with water until reaching $\mathrm{pH} 7.4$, filtered with a mesh, and freeze-dried. To obtain crude chitosan, crude chitin was $\mathrm{N}$-deacetylated with $50 \% \mathrm{w} / \mathrm{v} \mathrm{NaOH}$ solution for 6 hours at $125^{\circ} \mathrm{C}$. The mixture was rinsed several times with water to reach required $\mathrm{pH}$ and filtered using a mesh. Chitosan obtained was stored at $-20^{\circ} \mathrm{C}$.

2.3. Preparation of Carboxymethyl Chitosan (CM-Ch). CM-Ch was extracted from Sarcophaga and Chrysomya larvae and commercial chitosan (Sigma-Aldrich) as previously described [22]. In brief, $10 \mathrm{~g}$ of chitosan from Sarcophaga, Chrysomya, and commercial chitosan were dispersed in $50 \mathrm{~mL}$ distilled water for $30 \mathrm{~min}$, then $50 \mathrm{~mL}$ of isopropyl alcohol was added, and the samples spun at $300 \mathrm{rpm}$ at room temperature for $30 \mathrm{~min}$. Aliquots of $10 \mathrm{M}$ $\mathrm{NaOH}(15 \mathrm{~mL})$ were added prior to spinning for $45 \mathrm{~min}$. Monochloroacetic acid ( $30 \mathrm{~g}$ ) was added, and the mixture was incubated at $55^{\circ} \mathrm{C}$ for $1 \mathrm{~h}$. The solution was filtered and washed with $80 \% \mathrm{EtOH}(\mathrm{v} / \mathrm{v})$ several times to remove chloroacetic acid. The white-yellow powder obtained was dried for $24 \mathrm{~h}$ at $50^{\circ} \mathrm{C}$.

\subsection{Characterization of Chitosan and CM-Ch}

2.4.1. Fourier-Transform Infrared (FTIR) Spectroscopy Analysis. Infrared spectroscopy measurements were performed in the transmission mode using an FTIR spectrometer (Shimadzu FTIR-8400S, Japan). FTIR spectrum (frequency range of $\lambda=400-4000 \mathrm{~cm}^{-1}$ ) was determined for pellets containing $2 \mathrm{mg}$ of chitosan and CM-Ch samples in $200 \mathrm{mg}$ of $\mathrm{KBr}$.

2.4.2. Determination of the Degree of Deacetylation (DD) in Chitosan. DD was assessed using FTIR spectroscopy as described previously [23]. The DD was calculated using Baxter's equation [24]:

$$
\mathrm{DD}=100-\left[\frac{A_{1655}}{A_{3450}} \times \frac{100}{1.33}\right],
$$


where $A_{1655}$ is the absorbance of the amide-I bond as a measure of the N-acetyl group content and $A_{3450}$ of the N-H bond. The factor " 1.33 " denotes the value of the $A_{1655} / A_{3450}$ ratio for fully $\mathrm{N}$-acetylated chitosan.

2.4.3. Determination of the Molecular Weight of Chitosan. The intrinsic viscosity $[\eta]$ of $0.1 \%$ chitosan in $1 \% \mathrm{v} / \mathrm{v} \mathrm{AcOH}$ was measured using a viscometer. The viscosity averagemolecular weight $\left(\mathrm{M}_{\mathrm{wt}}\right)$ was calculated using the Mark-Houwink relationship [25]: $[\eta]=K . M_{\mathrm{wt}}^{a}$, where " $\eta$ " is the intrinsic viscosity and " $K$ " and " $a$ " are calculated as

$$
\begin{aligned}
& K=1.64 \times 10^{-30} \times(\% \mathrm{DD})^{14}, \\
& a=-1.02 \times 10^{-2} \times(\% \mathrm{DD})+1.82 .
\end{aligned}
$$

2.4.4. Proton Nuclear Magnetic Resonance ( ${ }^{1} H$ NMR) Spectroscopy. Water-soluble CM-Ch samples were dissolved in $1 \%$ DMSO. ${ }^{1} \mathrm{H}$ NMR spectrum of CM-Ch samples was recorded using a JEOL JNM-ECA-500 spectrometer under a static magnetic field of $500 \mathrm{MHz}$ at $25^{\circ} \mathrm{C}$.

2.4.5. Determination of CM-CH Molecular Weight by MALDI-TOF MS Analysis. The molecular weights of CMCh samples were determined by MALDI-TOF MS using 2,5-dihydroxybenzoic acid (DHB) as a sample matrix. The experiment was performed in an ultraflex TOF/TOF (Bruker Daltonics, Germany) in the positive reflection mode $(400-6000 \mathrm{~m} / z)$.

2.5. Cell Culture. HepG2 liver cancer cells were obtained from ATCC (USA) and maintained in the DMEM medium (Gibco) supplemented with 10\% fetal bovine serum, $100 \mathrm{U} / \mathrm{mL}$ penicillin, and $100 \mu \mathrm{g} / \mathrm{mL}$ streptomycin at $37^{\circ} \mathrm{C}$ in a $5 \% \mathrm{CO}_{2}$ incubator.

2.6. MTT Assay. Cells were seeded $\left(2 \times 10^{5}\right.$ cells/per well $)$ in a 96-well plate in complete DMEM medium. Cells were treated with increasing concentrations $(0-1200 \mu \mathrm{g} / \mathrm{mL})$ of different CM-Ch. After $48 \mathrm{~h}$, fresh medium, supplemented with $10 \mu \mathrm{L}$ of $12 \mathrm{mM}$ MTT (3-(4,5-dimethylthiazol-2-yl)2,5-diphenyltetrazolium bromide), was added, and cells were incubated for $4 \mathrm{~h}$ at $37^{\circ} \mathrm{C}$. The reaction was stopped after the addition of $100 \mu \mathrm{L}$ SDS-HCl. The microplate was incubated for $18 \mathrm{~h}$ at $37^{\circ} \mathrm{C}$. Absorbance $(A)$ was read at $545 \mathrm{~nm}$. The viability percentage was calculated using the formula $\left(\left(A_{\text {Treated }}-A_{\text {Blank }}\right) /\left(A_{\text {Control }}-A_{\text {Blank }}\right) \times 100\right)$. $\quad \mathrm{IC}_{50}$ was determined using a sigmoidal curve.

2.7. Morphological Analysis. Cells were subjected to increasing concentrations $(1-1000 \mu \mathrm{g} / \mathrm{mL})$ of CM-Ch for 24-72 h. Images were captured using an inverted phase contrast microscope at $400 \times$. Digital images were acquired with a Kodak microscopic digital camera.
2.8. Enzyme-Linked Immunosorbent Apoptosis Assay (ELISA). Cells were seeded $\left(2 \times 10^{4}\right.$ cells' per well $)$ in a 96well plate in complete DMEM medium. After $24 \mathrm{hrs}$, cells were treated with different $\mathrm{CM}-\mathrm{Ch}$ and incubated for an additional $48 \mathrm{~h}$. A cell death detection ELISA plus kit (Roche, USA) was used to quantify histone release from fragmented DNA. In brief, cells were lysed at room temperature for $30 \mathrm{~min}$. The lysates were centrifuged, and supernatant samples were incubated with antihistone biotin and antiDNA peroxidase at room temperature for $2 \mathrm{~h}$. After washing, a substrate solution (2,2' -azino-di(3-ethylbenzthiazolinsulphuric acid) was added, and samples were incubated for $20 \mathrm{~min}$ at room temperature. Absorbance $\left(\mathrm{OD}_{405}\right)$ was read using an ELISA reader (SpectraMax Plus).

2.9. Caspase-3 Activity. Caspase-3 activity was assayed calorimetrically following the manufacturer's protocol using the caspase- 3 assay kit (BioVision, Inc., CA, USA). Cells $\left(5 \times 10^{6}\right.$ cells/well $)$ were treated with or without CM-Ch and lysed with HEPES lysis buffer (10 mM HEPES pH 7.4, 2 mM EDTA, $0.1 \% 5 \mathrm{mM}$ CHAPS, $350 \mu \mathrm{g} / \mathrm{l}$ PMSF, and $5 \mathrm{mM}$ DTT). Lysates were centrifuged to remove cellular debris. Samples were supplemented with caspase- 3 substrate (AcDEVD-AFC) for $1 \mathrm{~h}$ at room temperature. The reaction was stopped with $1 \mathrm{~N} \mathrm{HCl}$. The absorbance $\left(\mathrm{OD}_{405}\right)$ was read using a spectrophotometer (Jenway Spectrophotometer, $\mathrm{UK})$.

2.10. $L D_{50}$ Determination. Lethal doses can be predicted from $\mathrm{IC}_{50}$ values [26]. A good estimate of the starting doses for in vivo acute oral toxicity tests can be obtained using the following equation:

$$
\log \left(\mathrm{LD}_{50}\right)=0.435 \times \log \left(\mathrm{IC}_{50}\right)+0.625 .
$$

\subsection{CM-Ch Oral Toxicity Study}

2.11.1. Animal Study. Healthy male albino rats (8 weeks, $\sim 90 \mathrm{~g}$ ) were used for the toxicity study. Animals were obtained from the Animal House of Alexandria University, Egypt. They were fed ad libitum with a standard diet and had free access to water. The animals were kept in standard polypropylene cages with a stainless-steel top grill and maintained at $23 \pm 2^{\circ} \mathrm{C}$ under conditions of $5 \pm 10 \%$ humidity and a $12 \mathrm{~h} \mathrm{light/dark} \mathrm{cycle.} \mathrm{Animals} \mathrm{were} \mathrm{adapted} \mathrm{for}$ three weeks prior to the commencement of the experiment. The use of laboratory animals and experimental procedures were conducted in accordance with the guidelines of the Animal Ethics Committee of Alexandria University, Egypt.

2.11.2. Dosing. Twenty rats were divided into four groups of five rats each. Three groups were given a single oral dose of half $\mathrm{LD}_{50}$ of different CM-Ch preparations at the start of the experimental period (15 days) [27]. One group served as the control and received a single oral dose of saline. Rats were observed daily for any clinical signs and abnormal physical or behavioral changes. Mortality was monitored during the 
experimental period. Blood samples were collected on day 15 and used for further analysis.

2.11.3. Body and Organ Weights. The body weights of rats were measured at least twice weekly. At the end of the experimental period, rats were anesthetized using cotton wool soaked in ether, and their final body weights were recorded. The liver, kidney, and spleen of rats were excised immediately. The organs were immediately weighed, and the organ weight ratio was calculated using the following equation:

$$
\text { organ weight ratio }=\frac{\text { organ weight }(g)}{\text { body weight }(g)} \times 100 .
$$

2.11.4. Determination of Biochemical Parameters. Blood samples were collected from the portal vein and kept to clot at room temperature for $30 \mathrm{~min}$ prior to centrifugation at $3000 \mathrm{rpm}$ for $10 \mathrm{~min}$ to separate serum from clotted blood. The serum was collected for biochemical tests. Separated sera were used to evaluate kidney and liver functions. For the kidney, serum urea and serum creatinine were assessed as previously described $[28,29]$. For the liver, serum aspartate aminotransferase (AST) and serum alanine aminotransferase (ALT) were assessed using a commercially available kit and following the instruction manual (BioSystems, Spain).

2.12. Statistical Analysis. Data are presented as mean$s \pm$ standard error of the mean (SEM) from at least three independent experiments. Data were subjected to one-way analysis of variance (ANOVA) using SPSS 10.0 software (SPSS, Chicago, IL, USA). The $p$ value was calculated vs. control cells: ${ }^{*} p<0.05,{ }^{* *} p<0.01,{ }^{* * *} p<0.005$, and **** $p<0.001$.

\section{Results}

3.1. Characterization of Chitosan and Carboxymethyl Chitosan (CM-Ch). The FTIR spectra of chitosan extracted from C. albiceps and S. aegyptiaca are shown in Figures 1(a) and $1(\mathrm{~b})$, respectively. FTIR analysis results of the CM-Ch preparations from chitosan extracted from both flies and commercial chitosan are shown in Figures 1(c)-1(e). The FTIR vibration bands of chitosan extracted from C. albiceps and S. aegyptiaca and FTIR vibration bands of CM-Ch prepared from chitosan extracted from C. albiceps (Ca-CMCh), S. aegyptiaca (Sa-CM-Ch), and commercial chitosan (sy-CM-Ch) are shown in Table 1.

From the absorbance ratio $A_{1655} / A_{3450}$, the degree of deacetylation (DD) of chitosan extracted from $C$. albiceps and S. aegyptiaca was $84 \%$ and $90 \%$, respectively. The viscosity average-molecular weights of chitosan extracted from C. albiceps and S. aegyptiaca larvae were 2.44 and $2.6 \mathrm{KDa}$, respectively. Peaks at 1614 and $1594 \mathrm{~cm}^{-1}$ were observed (Figures 1(a) and 1(b)), which were attributed to axial stretching of the $\mathrm{C}=\mathrm{O}$ bond of the acetamide (-CONH-) group of the acetylated chitosan units. The $\mathrm{C}-\mathrm{O}$ stretching vibration was recorded at 1080 and $1076 \mathrm{~cm}^{-1}$. The peaks at $3425 / 3435$ and $1446 / 1411 \mathrm{~cm}^{-1}$ are characteristics for $\mathrm{NH}_{2}$ and $\mathrm{C}-\mathrm{N}$ of the amine group, respectively. The peak intensity, characteristic for amine, at $3425 \mathrm{~cm}^{-1}$ for C. albiceps chitosan showed a lower intensity than that of $S$. aegyptiaca $\left(3435 \mathrm{~cm}^{-1}\right)$, which is consistent with the DD\% results. FTIR spectra of the CM-Ch (Figures $1(\mathrm{c})$ and $1(\mathrm{~d})$ ) revealed new peaks at $1728 \mathrm{~cm}^{-1}$, which is not in the spectra of chitosan extracted from both flies (Figures 1(a) and 1(b)). The spectrum of the CM-Ch prepared from commercial chitosan did not reveal a peak at $1728 \mathrm{~cm}^{-1}$ (Figure 1(e)). Additionally, a broadened and shifted peak at $3425 \mathrm{~cm}^{-1}$, due to the grafted carboxylate group, is evidence of successful CMCh formation (Figures 1(c)-1(e)).

${ }^{1} \mathrm{H}$ NMR analysis was used to further confirm CM-Ch preparations. The ${ }^{1} \mathrm{H}$ NMR spectrum of CM-Ch prepared from C. albiceps (Ca-CM-Ch), S. aegyptiaca (Sa-CM-Ch), and commercial chitosan (sy-CM-Ch) is shown in Figures 2(a)-2(c). The chemical shifts at 4 and $4.6 \mathrm{ppm}$ represent the $-\mathrm{CH}_{2}-\mathrm{COO}$ - protons substituted on $\mathrm{NH}_{2}$ of $\mathrm{CM}-\mathrm{Ch}_{2}$ and $\mathrm{OH}$ of $\mathrm{CM}-\mathrm{Ch}_{6}$, respectively. Similarly, the observed peak at 2.3 is for the $\mathrm{N}-\mathrm{C}-\mathrm{H}$ amine groups of chitosan that are substituted by $-\mathrm{CH}_{2} \mathrm{COOH}$. A small intensity peak at $1 \mathrm{ppm}$ corresponds to $\mathrm{N}-\mathrm{H}$ amine groups for unsubstituted amine groups in CM-Ch. The molecular weights of $\mathrm{Ca}-\mathrm{CM}-\mathrm{Ch}$, Sa-CM-Ch, and sy-CM-Ch were 545.2, 575.1, and 561.2 Da, respectively. These were estimated using the most significant peak from MALDI-TOF MS analysis (Figures 2(d)-2(f)).

3.2. CM-Ch Inhibits HepG2 Proliferation. To determine the potential cytotoxic effect of the three different preparations of CM-Ch on the HepG2 cells, cell viability was evaluated using an MTT colorimetric assay. Treatment of HepG2 cells with increasing concentrations $(0-1200 \mu \mathrm{g} / \mathrm{mL})$ of different CM-Ch compounds induced significant dose-dependent growth inhibition and reduced HepG2 cell viability after $48 \mathrm{~h}$ (Figure 3(a)). Semilogarithmic plotting of HepG2 cell viability percentage at increasing $\mathrm{CM}-\mathrm{Ch}$ concentrations was used to calculate $\mathrm{IC}_{50}$. HepG2 cells showed higher sensitivity towards both Sa-CM-Ch and sy-CM-Ch than they did towards Ca-CM-Ch. Calculated $\mathrm{IC}_{50}$ for the three different CM-Ch extracts was $480 \mu \mathrm{g} / \mathrm{mL}$ for either Sa-CM-Ch or syCM-Ch and $1100 \mu \mathrm{g} / \mathrm{mL}$ for Ca-CM-Ch (Figure 1(b)).

3.3. CM-Ch Induces Morphological Changes in HepG2 Cells. Treatment of HepG2 cells with increasing concentrations of CM-Ch $(0-1000 \mu \mathrm{g} / \mathrm{mL})$ caused morphological alterations after $48 \mathrm{~h}$ (Figure 4). Untreated cells showed high confluency rate and appeared as normal monolayer cells. Morphological alterations observed in cells treated with $\mathrm{CM}-\mathrm{Ch}$ include reduced cell dimensions, cell shrinkage, and chromatin condensation. These morphological changes become more obvious at higher doses. HepG2 cells treated with increasing concentrations of Ca-CM-Ch or Sa-CM-Ch, for $48 \mathrm{~h}$, displayed characteristic apoptotic features including reduced cell dimensions and cell shrinkage. The majority of cells exhibited a rounded shape after treatment with $300 \mu \mathrm{g} / \mathrm{mL}$ 


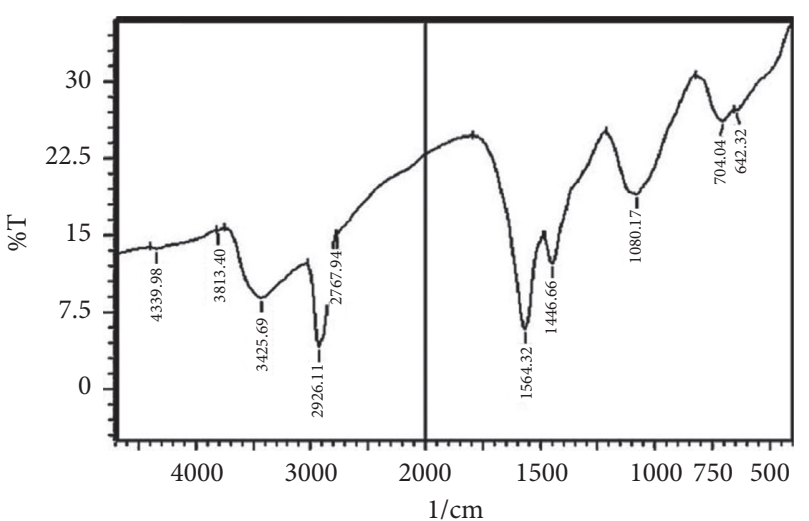

(a)

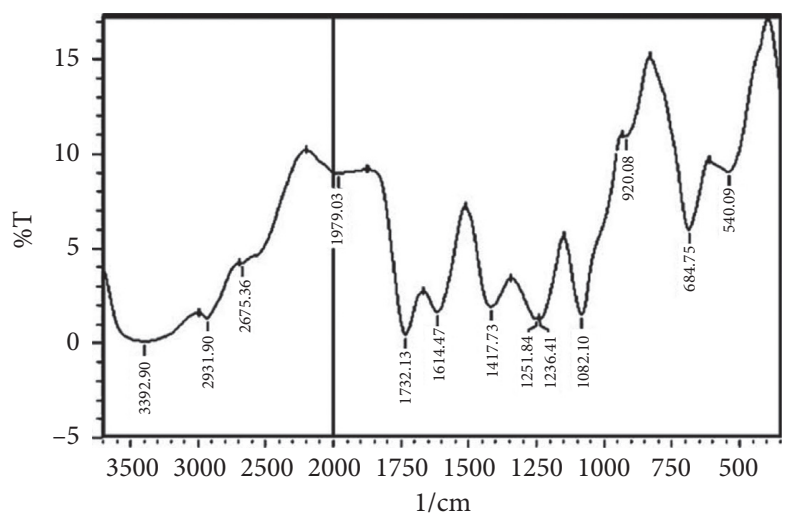

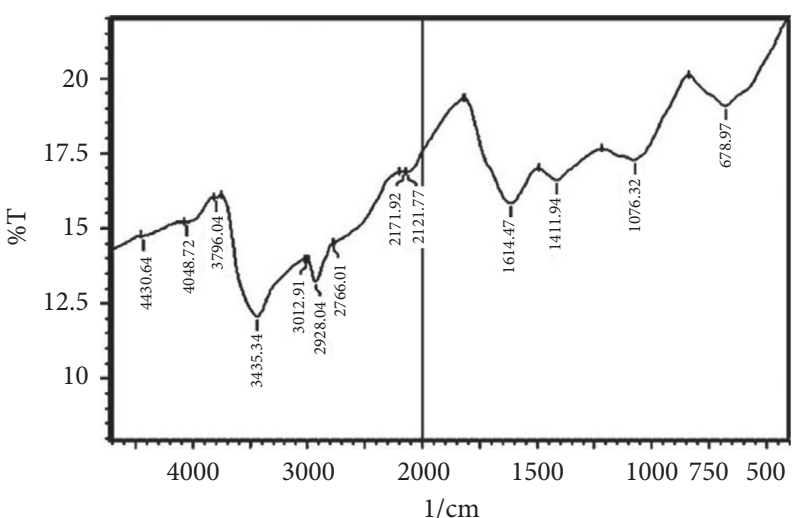

(b)

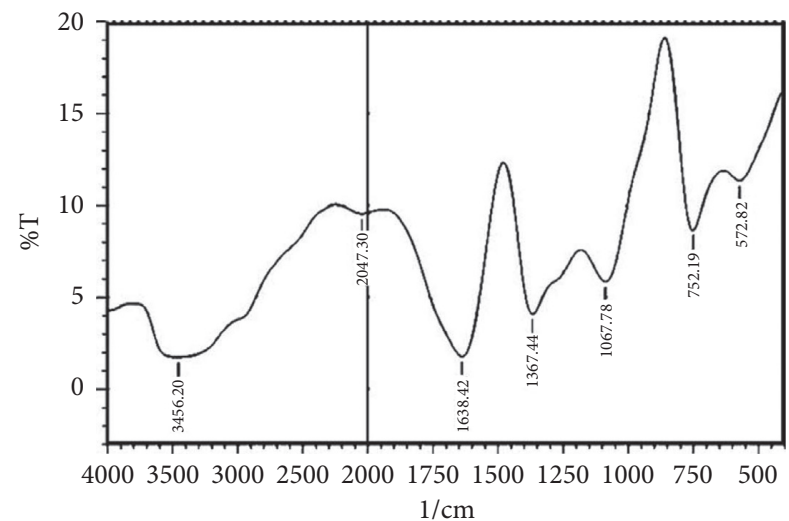

(d)

(c)

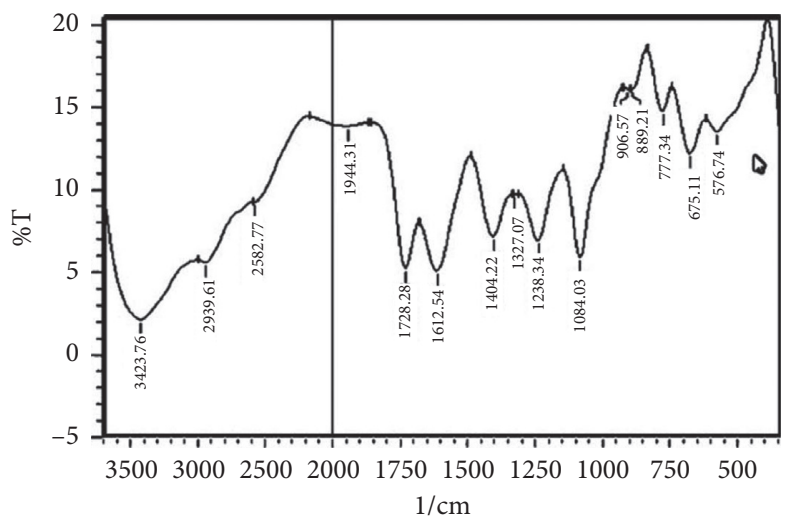

(e)

FIGURE 1: FTIR spectra of chitosan and carboxymethyl chitosan (CM-Ch). Spectra of chitosan extracted from Chrysomya albiceps (a) and Sarcophaga aegyptiaca (b). Spectra of the CM-Ch prepared from C. albiceps (c), S. aegyptiaca (d), and commercial crustacean chitosan (e).

CM-Ch. Chromatin condensation was detected, and the cellular morphology of HepG2 cells was severely distorted. Treatment of HepG2 cells with higher Ca-CM-Ch or Sa-CM$\mathrm{Ch}$ concentrations resulted in more distinct, clear morphological alterations with detached cells and weak cell-cell contact. HepG2 morphological changes were also observed after $72 \mathrm{~h}$ of treatment with sy-CM-Ch (Figure 4).

3.4. Apoptosis Is Induced in CM-Ch-Treated HepG2 Cells. We quantified histone release to assess apoptosis and to confirm inhibition of cell viability in HepG2 cells treated with Ca-CM-Ch, Sa-CM-Ch, and sy-CM-C. Apoptosis induction was significantly higher in cells treated with CM-Ch than in untreated cells (Figure 5(a)). The highest level of apoptosis was detected in Sa-CM-Ch-treated HepG2 cells.

\subsection{CM-Ch Compounds Induce Caspase-3 Activity in HepG2} Cells. Caspase activation characterizes the final pathway of apoptotic signal transduction. Detection of cleaved caspase-3 (activated caspase-3) confirms apoptosis induction. The three different CM-Ch compounds significantly increased the activation of caspase-3 in HepG2 cells 
TABLE 1: FTIR vibration bands of chitosan extracted from Chrysomya albiceps and Sarcophaga aegyptiaca and FTIR vibration bands of carboxymethyl chitosan prepared from chitosan extracted from C. albiceps (Ca-CM-Ch), S. aegyptiaca (Sa-CM-Ch), and commercial chitosan (sy-CM-Ch).

\begin{tabular}{|c|c|c|c|}
\hline \multirow{2}{*}{ Functional group } & & \multicolumn{2}{|c|}{ Frequency $\left(\mathrm{cm}^{-1}\right)$} \\
\hline & & C. albiceps chitosan & S. aegyptiaca chitosan \\
\hline \multicolumn{2}{|l|}{ Stretching vibration of $\mathrm{N}-\mathrm{H}$ and $-\mathrm{OH}$} & 3425 & 3435 \\
\hline \multicolumn{2}{|l|}{ Asymmetric $\mathrm{C}-\mathrm{H}$ stretching vibration } & 2926 & 2928 \\
\hline \multicolumn{2}{|l|}{ Symmetric C-H stretching vibration } & 2767 & 2766 \\
\hline \multicolumn{2}{|c|}{ Stretching vibration of $\mathrm{C}=\mathrm{O}$ bond of acetamide } & 1564 & 1614 \\
\hline \multicolumn{2}{|l|}{ Vibration of the $(\mathrm{C}-\mathrm{N})$ amine group } & 1446 & 1411 \\
\hline \multicolumn{2}{|l|}{ Stretching vibration of $\mathrm{C}-\mathrm{O}$} & 1080 & 1076 \\
\hline Characteristic group & $\mathrm{Ca}-\mathrm{CM}-\mathrm{Ch}$ & $\mathrm{Sa}-\mathrm{CM}-\mathrm{Ch}$ & sy-CM-Ch \\
\hline Vibration of $\mathrm{O}-\mathrm{H}$ of carboxylic groups & 3392 & 3456 & 3423 \\
\hline Deforming bending vibration of $\mathrm{N}-\mathrm{H}$ & 1732 & 1638 & 1728 \\
\hline Vibration of $\mathrm{C}=\mathrm{O}$ of carboxylic groups & 1417 & 1367 & 1404 \\
\hline Vibration of the $\mathrm{C}-\mathrm{O}-\mathrm{C}$ bond & 1082 & 1087 & 1084 \\
\hline
\end{tabular}

(Figure 5(b)). Sa-CM-Ch treatment resulted in the highest caspase- 3 activity of all tested CM-Ch compounds.

3.6. CM-Ch Treatment Shows No Signs of Toxicity and No Changes in Biochemical Markers of Albino Rats. We used the Registry of Cytotoxicity (RC) method to generate a model to forecast the lethal dose $\left(\mathrm{LD}_{50}\right)$ of each $\mathrm{CM}-\mathrm{Ch}$ treatment. $\mathrm{LD}_{50}$ values were calculated from $\mathrm{IC}_{50}$ values, as reported previously [26], using the $\mathrm{RC}$ regression equation:

$$
\log \left(\mathrm{LD}_{50}\right)=0.435 * \log \left(\mathrm{IC}_{50}\right)+0.625 .
$$

Calculated $\mathrm{LD}_{50}$ values were $3.1 \mathrm{~g} / \mathrm{kg}$ for $\mathrm{Ca}-\mathrm{CM}-\mathrm{Ch}$ and $2.2 \mathrm{~g} / \mathrm{kg}$ for $\mathrm{Sa}-\mathrm{CM}-\mathrm{Ch}$ and sy-CM-Ch. To evaluate the toxicity of CM-Ch, half of $\mathrm{LD}_{50}$ for each CM-Ch was orally administered to albino rats at the start of the 15-day experimental period. None of the treated rats died, and there were no signs of toxicity or behavioral changes when compared to the untreated control group. Furthermore, no conspicuous pathological changes were detected at necropsy in any of the rats at the end of the experimental period. Changes in mean body weights of the treated groups did not significantly differ from those in the untreated control group (Figure 6). Body and organ weight and comparisons revealed no significant differences between treatment groups and controls (Figure 6).

Kidney and liver functions were also investigated to further evaluate the biological safety of the three different CM-Ch compounds. Kidney function was evaluated by measuring urea and creatinine levels in treated and untreated groups. No significant difference in kidney parameters was observed between treated and untreated control groups (Figure 7). Serum AST and ALT activities were measured to assess liver function. No significant difference in liver parameters was observed in treated groups and untreated groups (Figure 7).

\section{Discussion}

The omnipresence of insects in any type of ecological system, from waterways to exceedingly infected environments, enables scientists to explore Arthropoda for different therapeutic agents [30]. Insects and their derived compounds may also have bioactive functions and should be considered a viable source of therapeutically effective medicines [31, 32]. The use of natural products has been the foremost successful approach to enhancing antitumor activity by modulating basic mechanisms [33]. This study was designed to explore the bioactivity of insect chitosan as a therapeutic agent against liver cancer. A low molecular weight, water-soluble chitosan derivative, $\mathrm{CM}-\mathrm{Ch}$, was prepared to assess its effect on the proliferation of HepG2 HCC cells and to evaluate its toxicity in rats.

The extraction of chitosan involved several steps, including field collection and laboratory rearing of the insect species, C. albiceps and S. aegyptiaca, followed by chitosan processing, including deproteination and deacetylation. The cuticle of crustaceans is typically composed of chitin in a mineral and protein matrix $[6,34]$. In contrast, the cuticle of insects consists of chitin in a matrix with lipids, cuticular proteins, and additional compounds [35]. Most insects contain insignificant amounts of minerals in their cuticle, so the demineralization process was not required [36, 37]. The average molecular weights of chitosan extracted from C. albiceps and S. aegyptiaca were lower than those of commercial chitosan. Moreover, chitosan extracted from C. albiceps and S. aegyptiaca had a relatively higher DD than did commercial chitosan, which is promising for further applications given that the DD of chitosan is proportional to its biological activity [38, 39].

The characteristic properties of chitosan extracted from C. albiceps and S. aegyptiaca were identified using FTIR analysis. The spectra resulting from $C$. albiceps and S. aegyptiaca larval chitosan were similar to those of chitosan extracted from Chrysomya megacephala larvae, Musca domestica larvae, chrysalides of the silkworm, and the exoskeletons of crabs and shrimps. The positions and intensities of characteristic peaks were almost identical to those reported previously [21, 40, 41]. The solubility of chitosan in moderate acidic conditions confers a severe disadvantage to many of its biologically possible applications [42]. Therefore, carboxymethylation was used to enhance chitosan processability and to strengthen some of its 


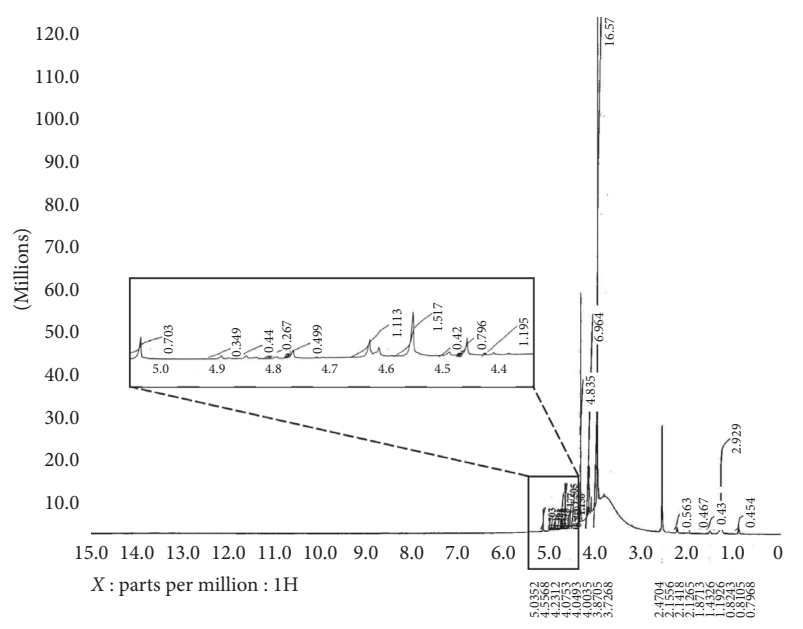

(a)

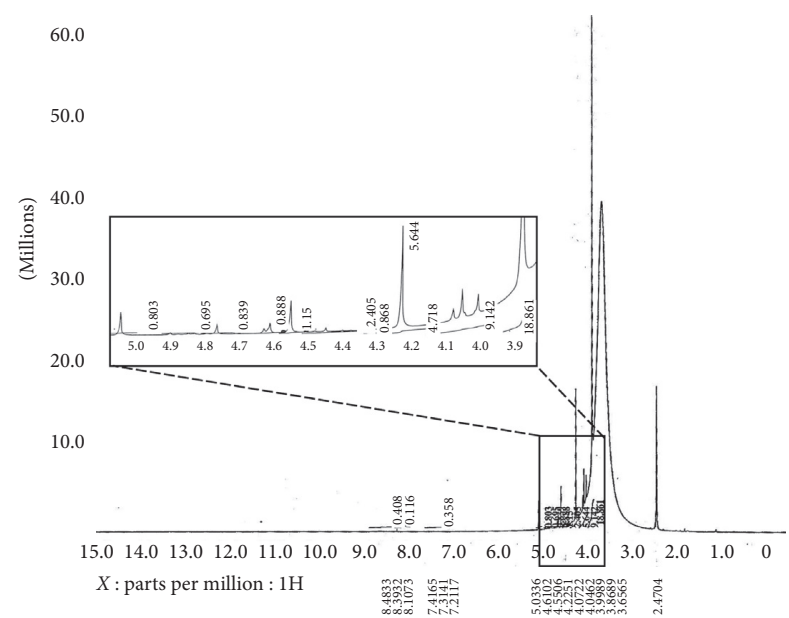

(c)

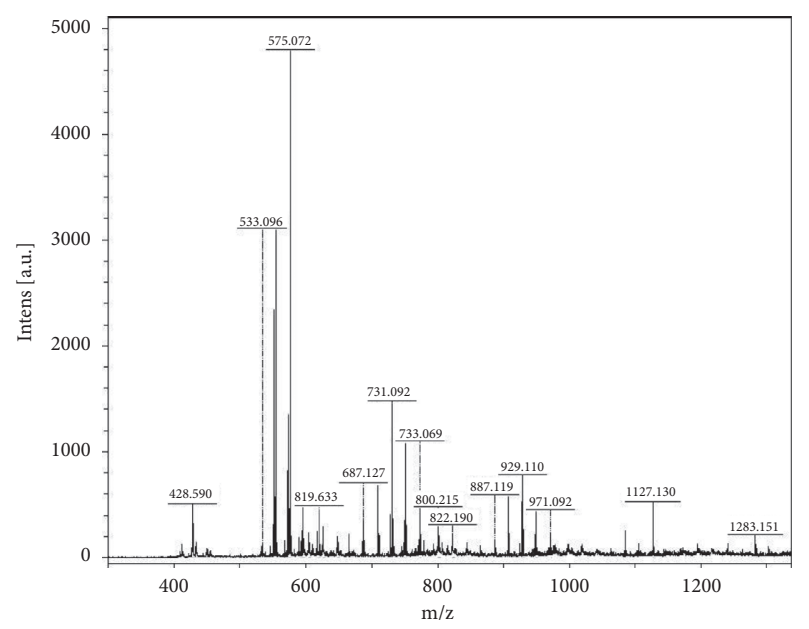

(e)

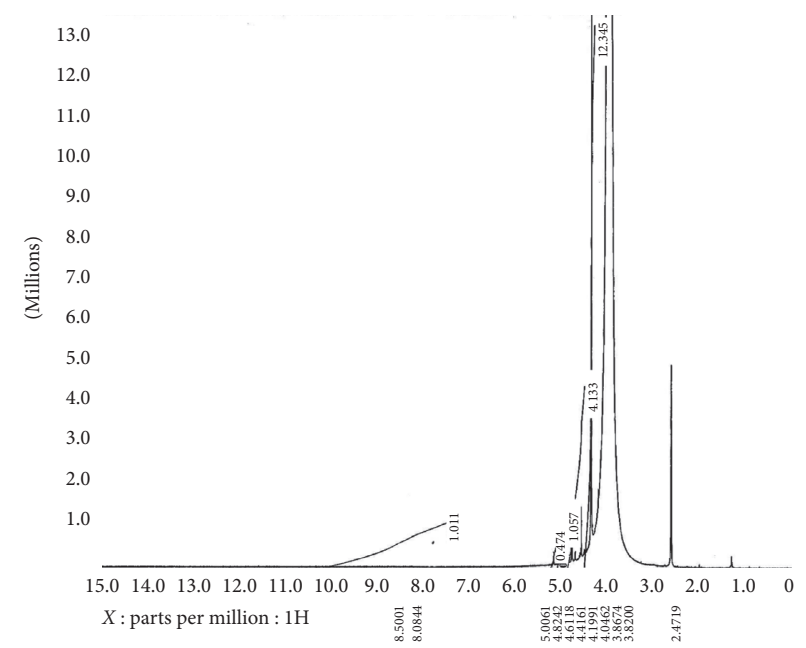

(b)

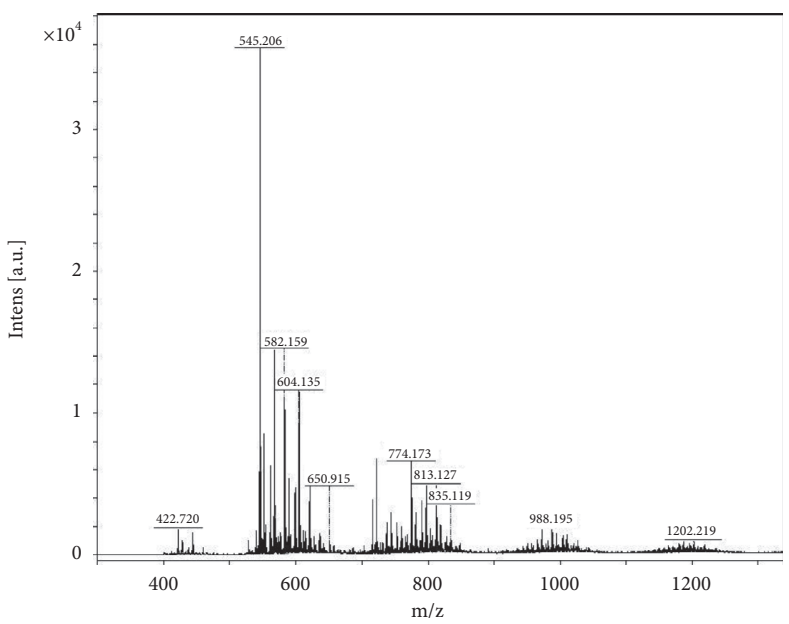

(d)

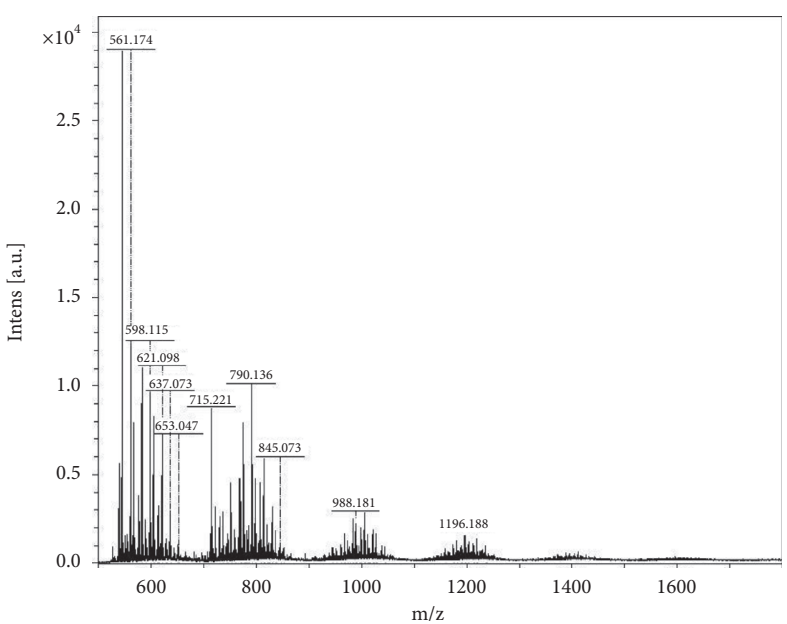

(f)

FIGURE 2: ${ }^{1} \mathrm{H}$ NMR spectra and molecular weights of carboxymethyl chitosan (CM-Ch). $\mathrm{H}^{1} \mathrm{NMR}$ spectra of Chrysomya albiceps CM-Ch (CaCM-Ch) (a), Sarcophaga aegyptiaca CM-Ch (Sa-CM-Ch) (b), and commercial chitosan CM-Ch (sy-CM-Ch) (c). Molecular weights of CaCM-Ch (d), Sa-CM-Ch (e), and sy-CM-Ch (f).

biological characteristics $[43,44]$. This step improved the biological activity of chitosan and may potentiate its activity as an antitumor agent in the future. The peaks observed at
1614 and $1594 \mathrm{~cm}^{-1}$ may be attributed to axial stretching of the $\mathrm{C}=\mathrm{O}$ bond of the acetamide (-CONH-) group of acetylated chitosan units [45]. The peak, characteristic for amine, 


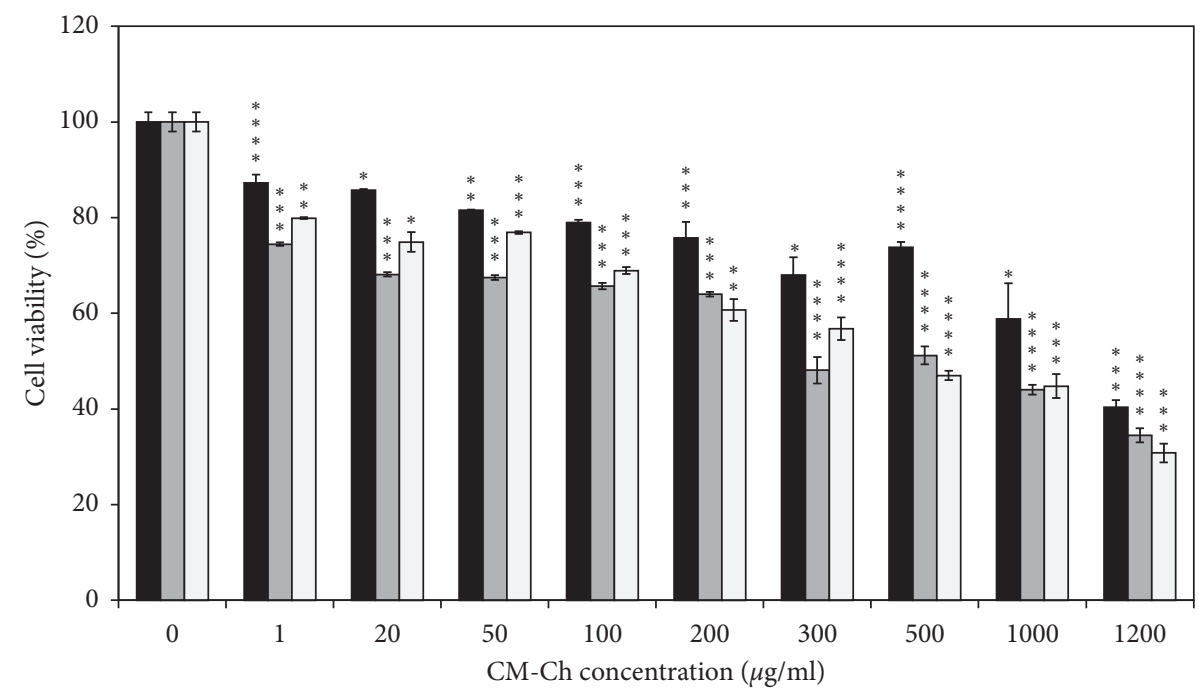

Ca-CM-Ch

$\square \mathrm{Sa}-\mathrm{CM}-\mathrm{Ch}$

$\square$ sy-CM-Ch

(a)

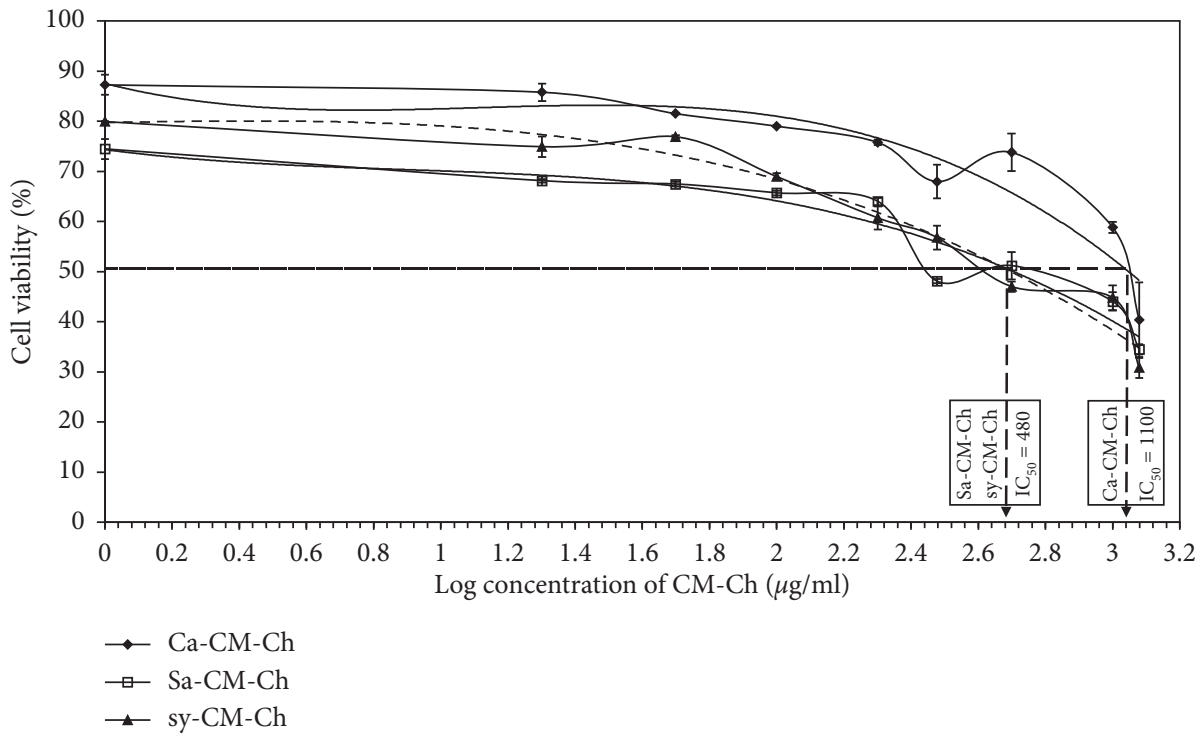

(b)

Figure 3: Effects of carboxymethyl chitosan (CM-Ch) on the viability of HepG2 cells. Cells were treated with CM-Ch (1-1200 $\mu \mathrm{g} / \mathrm{mL})$ for $48 \mathrm{~h}$. Controls were treated with DMSO only. (a) CM-Ch reduced HepG2 cell viability. (b) Semilogarithmic plotting of HepG2 cell viability at increasing CM-Ch concentrations was used to calculate $\mathrm{IC}_{50}$. Ca-CM-Ch, Chrysomya albiceps CM-Ch; Sa-CM-Ch, Sarcophaga aegyptiaca CM-Ch; sy-CM-Ch, CM-Ch of commercial chitosan. Data $(n=3)$ were presented as means \pm SEM. $p$ value was calculated vs. control cells: ${ }^{*} p<0.05,{ }^{* *} p<0.01,{ }^{* * *} p<0.005$, and ${ }^{* * * *} p<0.001$.

at $3400 \mathrm{~cm}^{-1}$ was less intense in C. albiceps than in S. aegyptiaca which was consistent with the DD\% results [46]. Additionally, the appearance of new peaks at 1728 and $1638 \mathrm{~cm}^{-1}$ in the spectra of CM-Ch prepared from chitosan extracted from both flies may be attributed to symmetric and antisymmetric stretching of the carboxylate group $\mathrm{C}=\mathrm{O}$ in $\mathrm{CM}-\mathrm{Ch}$ as reported previously [45]. The absence of the $1728 \mathrm{~cm}^{-1}$ peak in the spectrum of the $\mathrm{CM}-\mathrm{Ch}$ prepared from commercial chitosan may be due to the nature of the
CM-Ch produced, pure O-CM-Ch, while both O-CM-Ch and $\mathrm{N}-\mathrm{CM}-\mathrm{Ch}$ are formed in $\mathrm{CM}-\mathrm{Ch}$ preparations from insect chitosan, potentially causing an $\mathrm{N}-\mathrm{H}$ deformation leading a peak shift to the 1728 range [46]. This difference may have arisen because of the temperature used during the carboxylation process in this work. CM-Ch structural complexity is difficult to characterize and requires clear identification [47]. Consequently, the infrared spectra of chitosan and CM-Ch were compared using ${ }^{1} \mathrm{H}$ NMR 


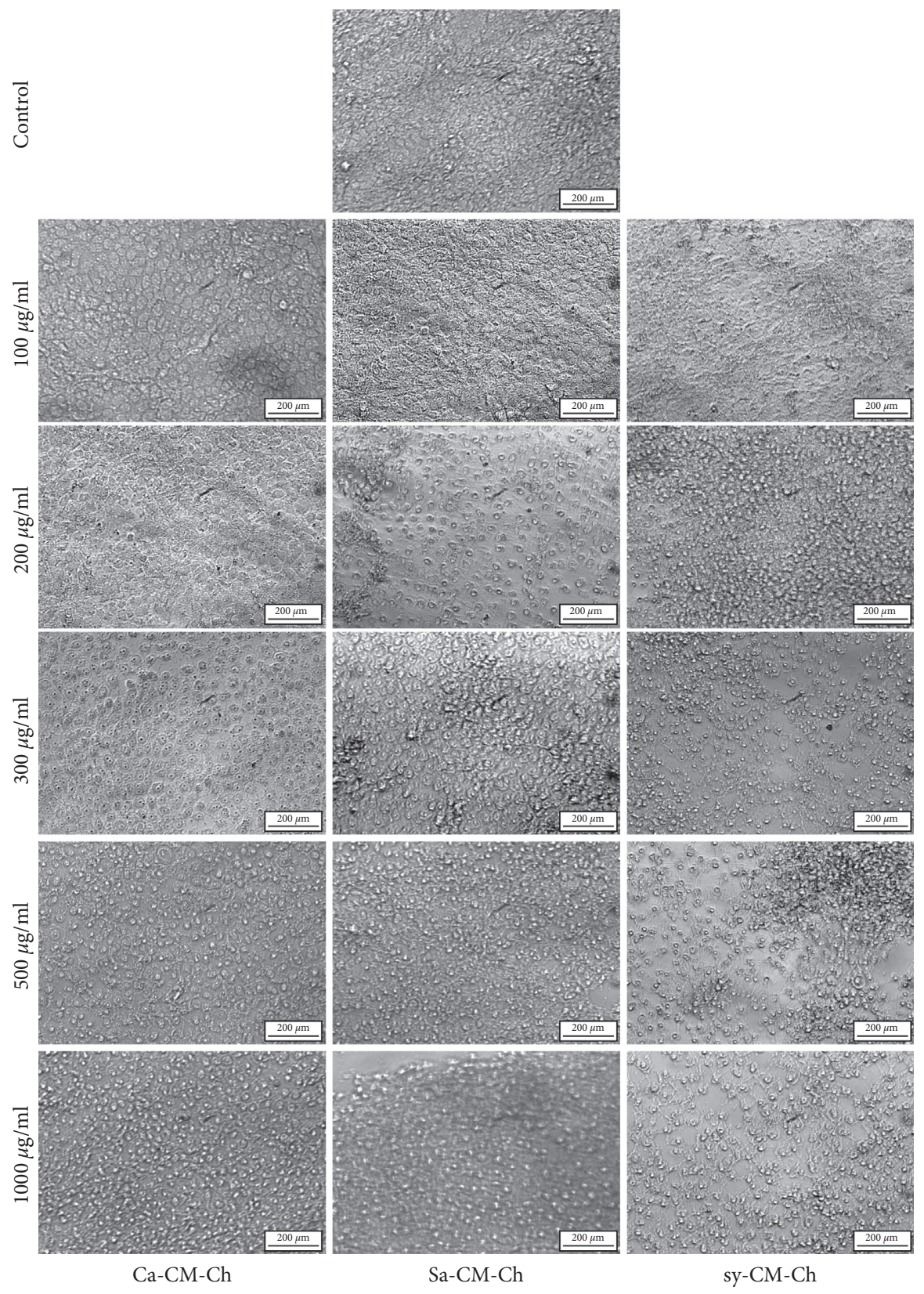

Figure 4: Carboxymethyl chitosan (CM-Ch) induced morphological changes in HepG2 cells. Cells were treated with the indicated concentrations of $\mathrm{CM}-\mathrm{Ch}$ for 48 or $72 \mathrm{~h}$ (sy-CM-Ch). Representative images were shown from three independent experiments. Ca-CM-Ch, Chrysomya albiceps CM-Ch; Sa-CM-Ch, Sarcophaga aegyptiaca CM-Ch; sy-CM-Ch, commercial chitosan CM-Ch. 400×.

spectroscopy to reveal the hydrophilic characteristics of CMCh compared to parental chitosan.

Despite the joint efforts of governments and researchers globally, the incidence of HCC has continued to rise over the last two decades [48]. Previous studies of chitosan and chitosan derivatives indicate that the inhibition of proliferation in tumors in vivo following chitosan treatment occurs by immune system stimulation through increasing lymphokine production and enhancing lymphocyte activity [49]. Here, we used HepG2 cells as a model for HCC to investigate the potential cytotoxic effects of CM-Ch. Treatment of HepG 2 cells with CM-Ch inhibited cell growth. To investigate the possible cytotoxic and antiproliferative effects of the three different CM-Ch extracts, Ca-CM-Ch, SaCM-Ch, and sy-CM-Ch on HepG2 cells, we performed MTT assays. Our results show that cell viability was reduced in a dose-dependent manner after 48 hrs of treatment. Similarly, another family of chitin and chitosan derivatives was shown to have antiproliferative effects on SMMC-7721 HHC cells [50].

The proliferation of A549 (human lung adenocarcinoma) and WiDr (colon adenocarcinoma) cancer cells was significantly inhibited by low-molecular weight chitosan extracted from mayfly, commercial low-molecular weight chitosan (LMWCc), and commercial medium-molecular weight chitosan (MMWCc) [51]. Additionally, LMWCc 


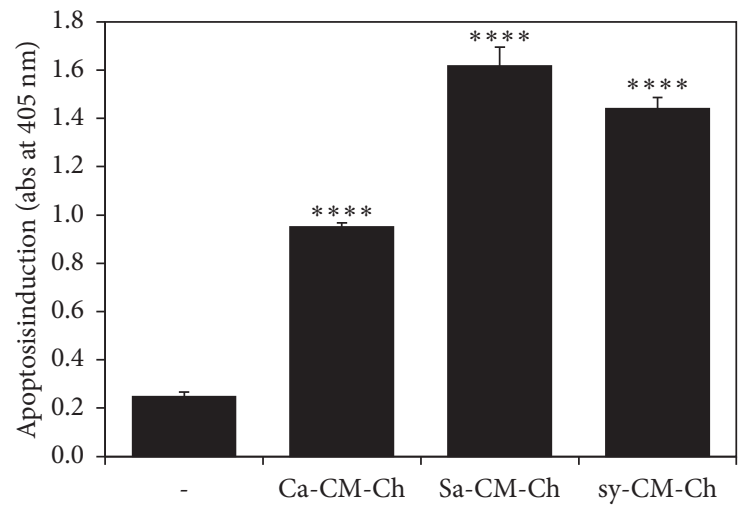

(a)

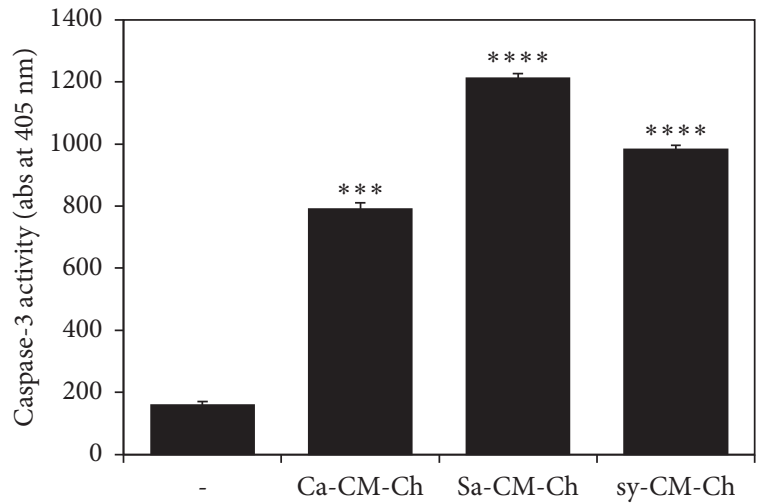

(b)

FIGURE 5: Carboxymethyl chitosan (CM-Ch) induced caspase-dependent apoptosis in HepG2 cells. Cells were either untreated or treated with the indicated CM-Ch $(300 \mu \mathrm{g} / \mathrm{mL})$ for $48 \mathrm{~h}$. Lysed cells were subjected to (a) enzyme-linked immunosorbent apoptosis assay to measure histone release as an indication of apoptosis; (b) caspase-3 activity assay. Each assay was performed in triplicate, and the standard error of the mean (SEM) was calculated. Data were presented as mean \pm SEM. $p$ value was calculated vs. control cells: ${ }^{* * *} p<0.005$ and ${ }^{* * * *} p<0.001$. Ca-CM-Ch, Chrysomya albiceps CM-Ch; Sa-CM-Ch, Sarcophaga aegyptiaca CM-Ch; sy-CM-Ch, CM-Ch of commercial chitosan.

exhibited higher antitumor activity towards HeLa (human epithelial cervical cancer) cells than did mayfly chitosan or MMWCS. Hence, the molecular weight, DD, and the animal source from which chitosan is obtained influence the activity of chitosan against cancer cell lines [51]. Here, low-molecular weight CM-Ch from different sources exhibited strong antiproliferation activity towards the HepG2 cell line with different $\mathrm{IC}_{50}$. While few studies have evaluated the inhibitory effect of CM-Ch on tumor cell lines, a previous study reported that CM-Ch has a slight inhibitory effect on proliferation in SGC-7901 (human gastric cancer), Bel-7402 (human hepatocellular carcinoma), and HeLa cancer cell lines only at high concentrations, up to $5 \mathrm{mg} / \mathrm{mL}$ [52]. Similar results showed that concentrations of 1 and $2 \mathrm{mg} / \mathrm{mL}$ $\mathrm{CM}-\mathrm{Ch}$ did not reduce proliferation in four cancer cell lines, OSRC-2 (renal cell carcinoma), SGC-7901, NCI-H1650 (lung adenocarcinoma), and HT-29 (colon adenocarcinoma), although significant reduction in cell viability was observed at higher concentrations [53]. The CM-Ch used in this study produced significant antiproliferative effects within a low concentration range and could be considered a promising anticancer reagent. Indeed, the carboxymethylation process could modify the biological characteristics of chitosan, and CM-Ch may show remarkably different and/or enhanced biological activities than does original chitosan.

The induction of apoptosis is an important pathophysiological strategy through which an ideal antitumor agent acts to stop cancer cell growth [54]. Apoptosis is typically characterized by morphological alterations and biochemical hallmarks in cells [48]. Morphological observation of CM-Ch-treated HepG2 cells revealed rounded-up cells with typical apoptotic phenotypes including cell shrinkage and chromatin condensation that may be due to the growth arrest and apoptotic induction after $\mathrm{CM}-\mathrm{Ch}$ treatment. The apoptosis-related morphological changes of HepG2 cells treated with $\mathrm{Ca}-\mathrm{CM}-\mathrm{Ch}$ and $\mathrm{Sa}-\mathrm{CM}-\mathrm{Ch}$ were clearly observed after $48 \mathrm{~h}$, while those treated with sy-CMCh exhibited similar morphological alterations after $72 \mathrm{~h}$. Additionally, HepG2 cells were more sensitive towards CM$\mathrm{Ch}$ extracted from insects than $\mathrm{CM}-\mathrm{Ch}$ derived from commercial chitosan. The observed differences in the activity of different CM-Ch preparations towards HepG2 cells could be because they were extracted from different animal sources. C. albiceps is a viviparous insect, while S. aegyptiaca is a larviparous insect. Differences in biology of oviposition and fecundity of females could affect the composition of chitin in the offspring, which could then affect the biological activities. However, this requires further investigation.

Nucleosomal histones are released from apoptotic chromatin which, kinetically, matches well with DNA fragmentation [55]. Our results indicate that the three different CM-Ch compounds tested significantly induce the release of histone from HepG2 cells. Apoptosis is regulated via a sequence of signal cascades, the intrinsic pathway, and the extrinsic pathway [56]. Both pathways are key molecular signaling pathways, involved in apoptosis and triggering the enzymatic caspase-cascade signaling system, leading to several proteolytic events mediating programmed cell death [57]. Caspase- 3 is common to both intrinsic and extrinsic apoptosis pathways [56]. The manifestation of the hitting effect of caspase- 3 on HepG2 cells, herein, was to confirm the induction of apoptosis by $\mathrm{CM}$-Ch treatment, demonstrating a significant elevation of the caspase- 3 activity after CM-Ch treatments. These results indicate that the observed inhibition of HepG2 cell growth following CM-Ch treatment may be attributed to the induction of apoptosis via caspase- 3 activation. The highest caspase- 3 activity was observed in cells treated with Sa-CM-Ch, and this bioactivity may be ascribed to its high DD [38]. Consistently, chitosan induced apoptosis in bladder tumor cells through caspase- 3 activation [58]. Further studies are required to focus on the signaling pathway through which CM-Ch triggers apoptosis in HepG2 cells. 


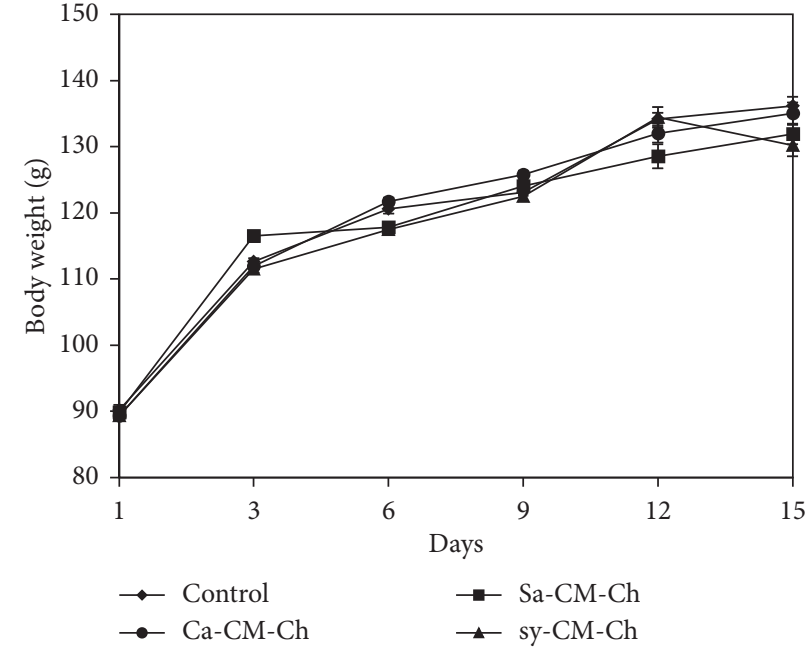

(a)

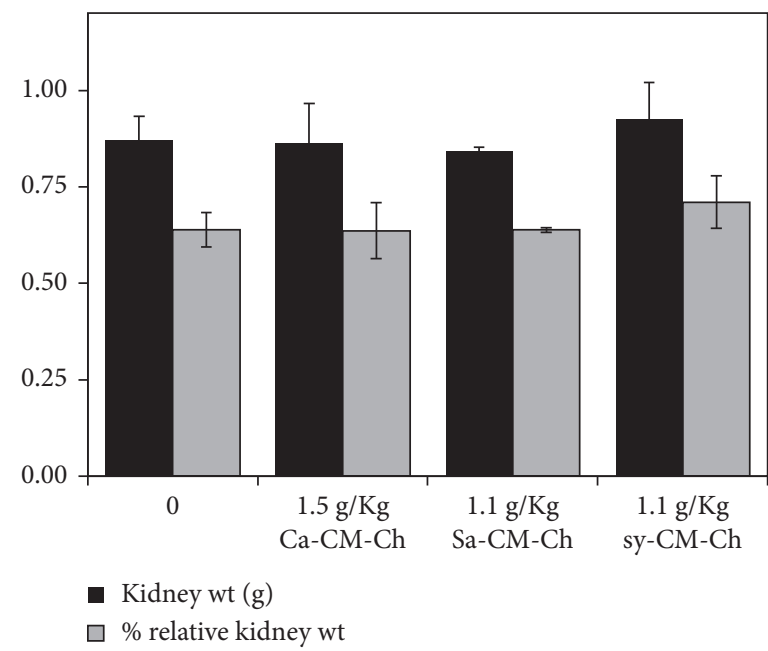

(c)

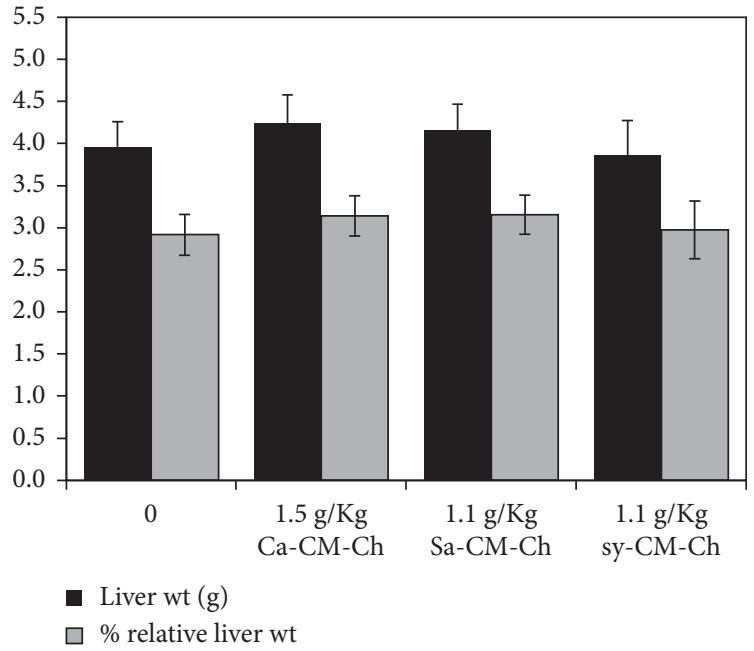

(b)

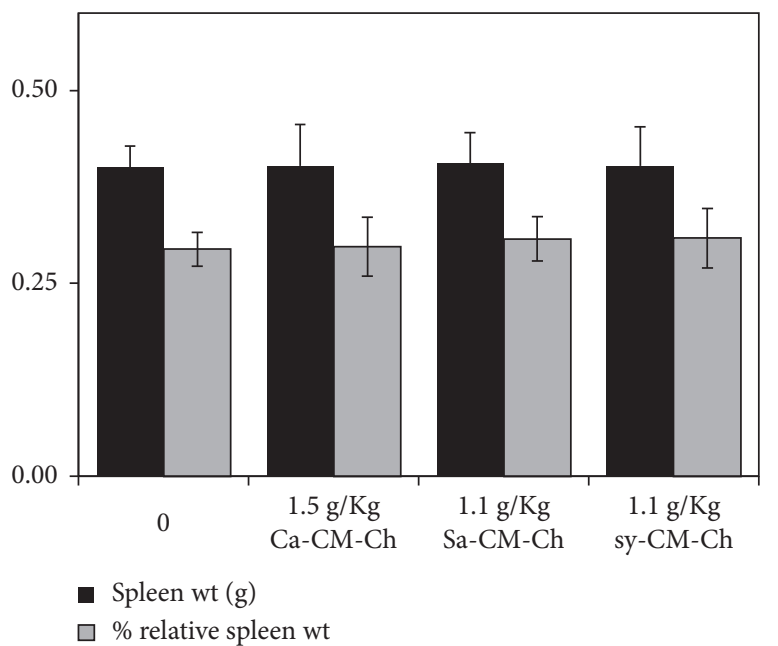

(d)

FIGURE 6: CM-Ch treatment did not affect body weight, organ weight, and percentage of organ weight relative to body weight in rats. Animals were treated with a single oral dose of either Ca-CM-Ch $(1.5 \mathrm{~g} / \mathrm{kg}), \mathrm{Sa}-\mathrm{CM}-\mathrm{Ch}(1.1 \mathrm{~g} / \mathrm{kg}), \mathrm{sy}-\mathrm{CM}-\mathrm{Ch}(1.1 \mathrm{~g} / \mathrm{kg})$, or saline $(1 \mathrm{~mL} / \mathrm{kg})$ as a control. Body weight, organ weight, and percentage of organ weight relative to body weight were measured after 15 days of treatment. Data were represented as mean \pm SEM of five animals. Ca-CM-Ch, Chrysomya albiceps CM-Ch; Sa-CM-Ch, Sarcophaga aegyptiaca CM-Ch; sy-CM-Ch, CM-Ch of commercial chitosan. Body and organ weights and percentage of kidney, liver, and spleen organ weight relative to body weight did not significantly differ between treated groups and controls.

Several studies have revealed the biological safety of CMCh in vitro. Treatment of human umbilical vein endothelial cells (HUVECs) with different concentrations of CM-Ch showed no significant decrease in cell viability after 24 and $48 \mathrm{hrs}$ of incubation and that $0.5-1.5 \mathrm{mg} / \mathrm{mL}$ of $\mathrm{CM}-\mathrm{Ch}$ was nontoxic to HUVECs [59]. Similarly, CM-Ch was nontoxic to L02 human normal liver cells [52]. Furthermore, a previous study on chitin derivatives showed that $O$-carboxymethyl chitin exhibited no cytotoxic activity on MRC-5 human normal lung fibroblastic cells at concentrations lower than or equal to $2 \mathrm{mg} / \mathrm{mL}$ [60]. Determining toxicity is a fundamental step in the evaluation of the safely of CM-Ch compounds. Therefore, we assessed the safety of insectderived CM-Ch by studying the biochemical parameters in rats. Previous studies reported that $\mathrm{CM}$-Ch had insignificant toxicity in rats $[27,61]$. We assessed the toxic effects of treatment with $\mathrm{CM}-\mathrm{Ch}$ by monitoring noticeable morphological and behavioral signs and weight changes and by determining the activity of some key liver and kidney enzymes. The lack of changes in AST, ALT, urea, and creatinine levels for all investigated CM-Ch compounds shows that there is no evidence of any liver or renal toxicity in the treated animals. Presumptively, it may be concluded that the oral administration of CM-Ch, prepared from chitosan that was extracted from the larvae of C. albiceps, S. aegyptiaca, and commercial crustacean chitosan, to rats is safe and does not affect any of the investigated biochemical parameters.

\section{Conclusion}

In drug discovery from natural sources, insects are one of the least investigated groups. Insect therapeutics represents a 


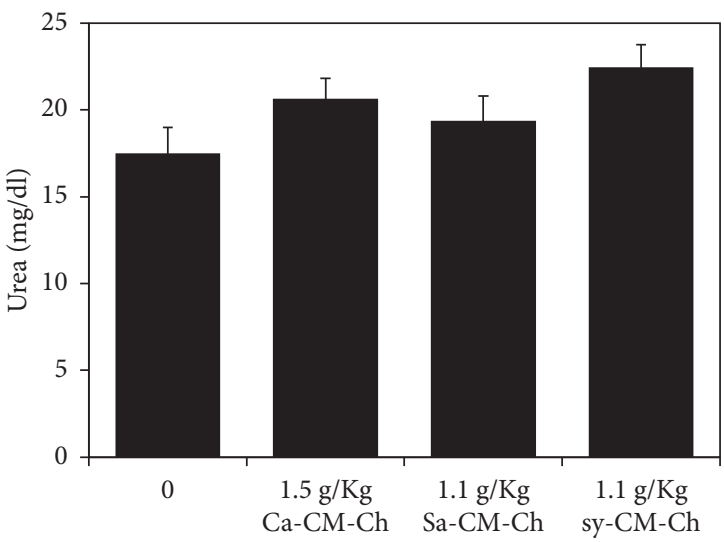

(a)

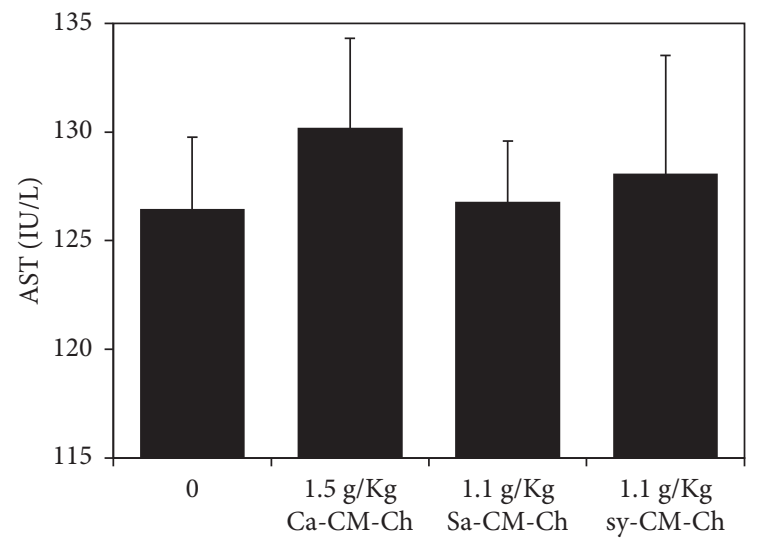

(c)

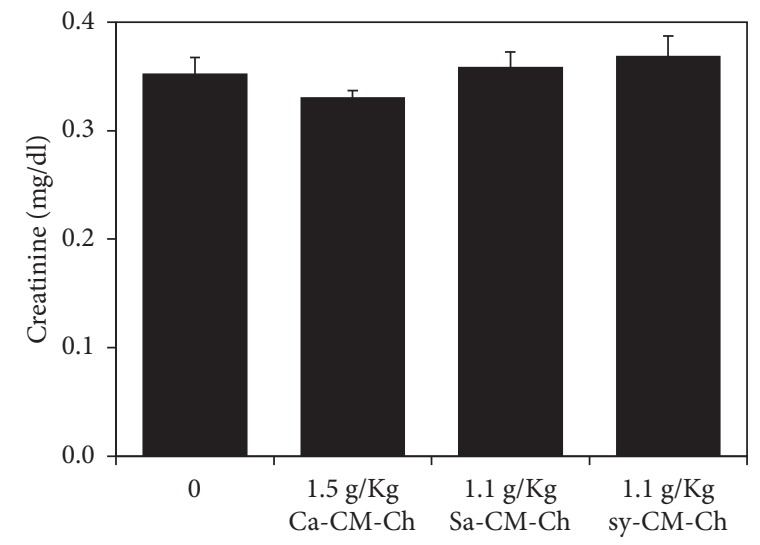

(b)

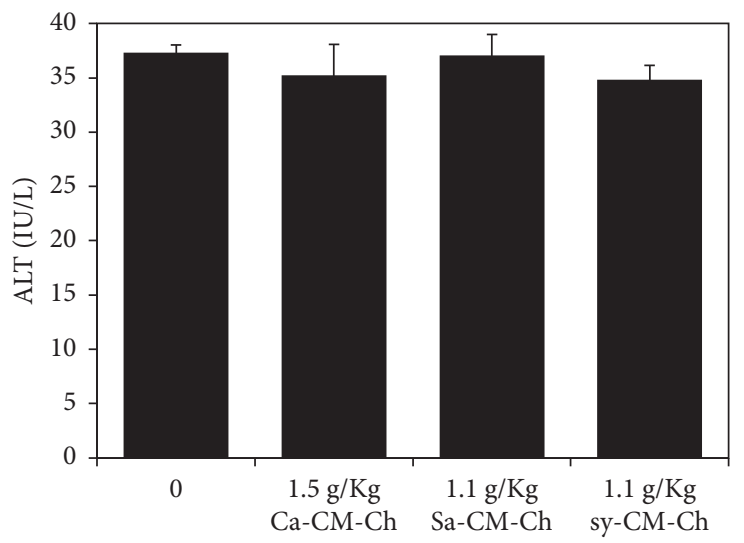

(d)

FIGURE 7: Kidney and liver biochemical parameters in rats treated with CM-Ch. Animals were treated with a single oral dose of either CaCM-Ch $(1.5 \mathrm{~g} / \mathrm{kg})$, Sa-CM-Ch $(1.1 \mathrm{~g} / \mathrm{kg})$, sy-CM-Ch $(1.1 \mathrm{~g} / \mathrm{kg})$, or saline $(1 \mathrm{~mL} / \mathrm{kg})$ as a control. Biochemical parameters of the kidney (serum urea and creatinine) and liver (AST and ALT) were measured after 15 days of treatment. Data were presented as mean \pm SEM of five animals. Ca-CM-Ch, Chrysomya albiceps CM-Ch; Sa-CM-Ch, Sarcophaga aegyptiaca CM-Ch; sy-CM-Ch, CM-Ch of commercial chitosan. No significant difference in liver and kidney parameters was observed in treated groups and controls.

significant untapped field of novel pharmaceutics. CM-Ch from insect sources could be a potent and inexhaustible commercially produced agent. Indeed, CM-Ch is effective to reduce cell viability and growth in HepG2 cells by inducing apoptosis without exerting any toxic effects in vivo. More investigations will validate the compelling chemopreventive capacities of CM-Ch in other cancer models. If chitosan or its derivatives demonstrate chemopreventive capabilities in vivo, they might be useful therapeutic agents for liver malignancy.

\section{Data Availability}

The data used to support the findings of this study are available from the corresponding author upon request.

\section{Conflicts of Interest}

The authors declare that there are no conflicts of interest regarding the publication of this article.

\section{Acknowledgments}

The authors extend their appreciation to the Deanship of Scientific Research at King Saud University, Riyadh, Saudi Arabia for funding this work through research group no. RG-1441-356.

\section{References}

[1] M. Pinter and M. Peck-Radosavljevic, "Review article: systemic treatment of hepatocellular carcinoma," Alimentary Pharmacology \& Therapeutics, vol. 48, 2018.

[2] A. A. S. El-Sherif, "Diagnostic outcomes of soluble major histocompatibility complex class I related chain molecule A and des-[gamma] carboxy prothrombin versus alpha-FetoProtein for hepatitis C virus-induced hepatocellular carcinoma in Egyptian patients," Immunome Research, vol. 12, no. 3, p. 1, 2016.

[3] H. Ai, F. Wang, Q. Yang, F. Zhu, and C. Lei, "Preparation and biological activities of chitosan from the larvae of housefly, Musca domestica," Carbohydrate Polymers, vol. 72, no. 3, pp. 419-423, 2008. 
[4] S. Mondal, S. Bandyopadhyay, K. Ghosh, S. Mukhopadhyay et al., "Natural products: promising resources for cancer drug discovery," Anti-Cancer Agents in Medicinal Chemistry, vol. 12, no. 1, pp. 49-75, 2012.

[5] Y. Feng, M. Zhao, Z. He, Z. Chen, and L. Sun, "Research and utilization of medicinal insects in China," Entomological Research, vol. 39, no. 5, pp. 313-316, 2009.

[6] M. Abbas, "Extraction of high thermally stable and nanofibrous chitin from Cicada (Cicadoidea)," Entomological Research, vol. 48, no. 6, pp. 480-489, 2018.

[7] Y. Maeda and Y. Kimura, "Antitumor effects of various lowmolecular-weight chitosans are due to increased natural killer activity of intestinal intraepithelial lymphocytes in sarcoma 180-bearing mice," The Journal of Nutrition, vol. 134, no. 4, pp. 945-950, 2004.

[8] T. K. Varun, S. Senani, N. Jayapal, J. Chikkerur et al., "Extraction of chitosan and its oligomers from shrimp shell waste, their characterization and antimicrobial effect," Veterinary World, vol. 10, no. 2, pp. 170-175, 2017.

[9] A. Khanafari, R. Marandi, and S. Sanatei, "Recovery of chitin and chitosan from shrimp waste by chemical and microbial methods," Iranian Journal of Environmental Health Science \& Engineering, vol. 5, no. 1, pp. 1-24, 2008.

[10] S.-K. Kim, Marine Medicinal Foods: Implications and Applications-Animals and Microbes, Vol. 65, Academic Press, Cambridge, MA, USA, 2012.

[11] M.-W. Kim, Y. S. Han, Y. H. Jo, M. H. Choi et al., "Extraction of chitin and chitosan from housefly, Musca domestica, pupa shells," Entomological Research, vol. 46, no. 5, pp. 324-328, 2016.

[12] C. Chokradjaroen, R. Rujiravanit, A. Watthanaphanit, S. Theeramunkong et al., "Enhanced degradation of chitosan by applying plasma treatment in combination with oxidizing agents for potential use as an anticancer agent," Carbohydrate Polymers, vol. 167, pp. 1-11, 2017.

[13] A. Muxika, A. Etxabide, J. Uranga, P. Guerrero, and K. de la Caba, "Chitosan as a bioactive polymer: processing, properties and applications," International Journal of Biological Macromolecules, vol. 105, no. 2, pp. 1358-1368, 2017.

[14] K. Raafat and W. Samy, "Amelioration of diabetes and painful diabetic neuropathy by punica granatum L. Extract and its spray dried biopolymeric dispersions," Evidence-Based Complementary and Alternative Medicine, vol. 2014, Article ID 180495, 12 pages, 2014.

[15] H. Zhang, "Hypoglycemic properties of oxovanadium (IV) coordination compounds with carboxymethyl-carrageenan and carboxymethyl-chitosan in alloxan-induced diabetic mice," Evidence-Based Complementary and Alternative Medicine, vol. 2011, Article ID 691067, 14 pages, 2011.

[16] N. H. AbdelAllah, "Chitosan and sodium alginate combinations are alternative, efficient, and safe natural adjuvant systems for hepatitis B vaccine in mouse model," EvidenceBased Complementary and Alternative Medicine, vol. 2016, Article ID 7659684, 9 pages, 2016.

[17] C.-S. Kong, J.-A. Kim, B. Ahn, H.-G. Byun, and S.-K. Kim, "Carboxymethylations of chitosan and chitin inhibit MMP expression and ROS scavenging in human fibrosarcoma cells," Process Biochemistry, vol. 45, no. 2, pp. 179-186, 2010.

[18] Z. Jiang, B. Han, H. Li, Y. Yang, and W. Liu, "Carboxymethyl chitosan represses tumor angiogenesis in vitro and in vivo," Carbohydrate Polymers, vol. 129, pp. 1-8, 2015.
[19] K. L. Sukontason, "Sarcophaga (Liosarcophaga) dux (Diptera: sarcophagidae): a flesh fly species of medical importance," Biological Research, vol. 47, no. 14, pp. 1-9, 2014.

[20] A. M. Salem, F. K. Adham, and C. J. Picard, "Survey of the genetic diversity of forensically important Chrysomya (Diptera: calliphoridae) from Egypt," Journal of Medical Entomology, vol. 52, no. 3, pp. 320-328, 2015.

[21] L. Miao and Y.-J. Wu, "Preparation and characterisation of food-grade chitosan from housefly larvae," Czech Journal of Food Sciences, vol. 29, no. 6, pp. 616-623, 2011.

[22] E. Soliman, E.-S. Mansour, H. Hassan, and N. Hassan, "Optimization of graft polymerization and performance of carboxymethyl chitosan/polyacrylamide flocculants," Journal of Research \& Developments in Chemistry, vol. 1, no. 1, pp. 1-18, 2014.

[23] S. Sabnis and L. H. Block, "Improved infrared spectroscopic method for the analysis of degree of N-deacetylation of chitosan," Polymer Bulletin, vol. 39, no. 1, pp. 67-71, 1997.

[24] A. Baxter, M. Dillon, K. D. Anthony Taylor, and G. A. F. Roberts, "Improved method for i.r. determination of the degree of $\mathrm{N}$-acetylation of chitosan," International Journal of Biological Macromolecules, vol. 14, no. 3, pp. 166-169, 1992.

[25] Z. Jia and D. Shen, "Effect of reaction temperature and reaction time on the preparation of low-molecular-weight chitosan using phosphoric acid," Carbohydrate Polymers, vol. 49, no. 4, pp. 393-396, 2002.

[26] W. Halle, "The Registry of Cytotoxicity: toxicity testing in cell cultures to predict acute toxicity (LD50) and to reduce testing in animals," Alternatives to Laboratory Animals: ATLA, vol. 31, no. 2, pp. 89-198, 2002.

[27] Z. Yang, B. Han, D. Fu, and W. Liu, "Acute toxicity of high dosage carboxymethyl chitosan and its effect on the blood parameters in rats," Journal of Materials Science: Materials in Medicine, vol. 23, no. 2, pp. 457-462, 2012.

[28] A. Tabacco, F. Meiattini, E. Moda, and P. Tarli, "Simplified enzymic/colorimetric serum urea nitrogen determination," Clinical Chemistry, vol. 25, no. 2, pp. 336-337, 1979.

[29] D. L. Fabiny and G. Ertingshausen, "Automated reaction-rate method for determination of serum creatinine with the CentrifiChem," Clinical Chemistry, vol. 17, no. 8, pp. 696-700, 1971.

[30] S. Chernysh, S. I. Kim, G. Bekker, V. A. Pleskach et al., "Antiviral and antitumor peptides from insects," Proceedings of the National Academy of Sciences, vol. 99, no. 20, pp. 12628-12632, 2002.

[31] N. Ratcliffe, P. Azambuja, and C. B. Mello, "Recent advances in developing insect natural products as potential modern day medicines," Evidence-Based Complementary and Alternative Medicine, vol. 2014, Article ID 904958, 21 pages, 2014.

[32] L. Seabrooks and L. Hu, "Insects: an underrepresented resource for the discovery of biologically active natural products," Acta Pharmaceutica Sinica B, vol. 7, no. 4, pp. 409-426, 2017.

[33] D. J. Newman and G. M. Cragg, "Natural products as sources of new drugs over the 30 years from 1981 to 2010," Journal of Natural Products, vol. 75, no. 3, pp. 311-335, 2012.

[34] F. Boßelmann, P. Romano, H. Fabritius, D. Raabe, and M. Epple, "The composition of the exoskeleton of two crustacea: the American lobster Homarus americanus and the edible crab Cancer pagurus," Thermochimica Acta, vol. 463, no. 1-2, pp. 65-68, 2007.

[35] J. L. Nation, Insect Physiology and Biochemistry, Taylor \& Francis, Oxford, UK, 2001.

[36] M. D. Finke, "Estimate of chitin in raw whole insects," Zoo Biology, vol. 26, no. 2, pp. 105-115, 2007. 
[37] P. Oduor-Odeto, M. Struszezyk, and M. G. Peter, "Characterisation of chitosan from blowfly larvae and some Crustacean species from Kenyan marin waters prepared under different conditions," Western Indian Ocean Journal of $\mathrm{Ma}$ rine Science, vol. 4, no. 1, pp. 99-108, 2007.

[38] G. I. Howling, P. W. Dettmar, P. A. Goddard, F. C. Hampson et al., "The effect of chitin and chitosan on the proliferation of human skin fibroblasts and keratinocytes in vitro," Biomaterials, vol. 22, no. 22, pp. 2959-2966, 2001.

[39] X. He, K. Li, R. Xing, S. Liu et al., "The production of fully deacetylated chitosan by compression method," The Egyptian Journal of Aquatic Research, vol. 42, no. 1, pp. 75-81, 2016.

[40] C. Song, H. Yu, M. Zhang, Y. Yang, and G. Zhang, "Physicochemical properties and antioxidant activity of chitosan from the blowfly Chrysomya megacephala larvae," International Journal of Biological Macromolecules, vol. 60, pp. 347-354, 2013.

[41] E. S. Abdou, K. S. A. Nagy, and M. Z. Elsabee, "Extraction and characterization of chitin and chitosan from local sources," Bioresource Technology, vol. 99, no. 5, pp. 1359-1367, 2008.

[42] Q. Cai-qin, D. Yu-min, X. Ling, G. Xiao-hai et al., "Effect of molecular weight and structure on antitumor activity of oxidized chitosan," Wuhan University Journal of Natural Sciences, vol. 7, no. 2, pp. 231-236, 2002.

[43] V. Balan and L. Verestiuc, "Strategies to improve chitosan hemocompatibility: a review," European Polymer Journal, vol. 53, pp. 171-188, 2014.

[44] A. Pavinatto, "Chemically modified chitosan derivatives," Frontiers in Biomaterials: Chitosan Based Materials and Its Applications, vol. 3, pp. 107-132, 2017.

[45] M. Kaya, Y. S. Cakmak, T. Baran, M. Asan-Ozusaglam et al., "New chitin, chitosan, and O-carboxymethyl chitosan sources from resting eggs of Daphnia longispina (Crustacea); with physicochemical characterization, and antimicrobial and antioxidant activities," Biotechnology and Bioprocess Engineering, vol. 19, no. 1, pp. 58-69, 2014.

[46] B. Doshi, E. Repo, J. P. Heiskanen, J. A. Sirviö, and M. Sillanpää, "Effectiveness of N,O-carboxymethyl chitosan on destabilization of Marine Diesel, Diesel and Marine-2T oil for oil spill treatment," Carbohydrate Polymers, vol. 167, pp. 326-336, 2017.

[47] F. R. de Abreu and S. P. Campana-Filho, "Characteristics and properties of carboxymethylchitosan," Carbohydrate Polymers, vol. 75, no. 2, pp. 214-221, 2009.

[48] M. S. Alwhibi, "Potential antitumor activity and apoptosis induction of glossostemon bruguieri root extract against hepatocellular carcinoma cells," Evidence-Based Complementary and Alternative Medicine, vol. 2017, Article ID 7218562, 21 pages, 2017.

[49] M. Z. Karagozlu and S.-. Kim, "Antiancer effects of chitinand chitosan derivatives," in Handbook of Anticancer Drugs from Marine Origin, S.-. Kim, Ed., pp. 413-421, Springer International Publishing, Berlin, Germany, 2015.

[50] Q. Xu, J. Dou, P. Wei, C. Tan et al., "Chitooligosaccharides induce apoptosis of human hepatocellular carcinoma cells via up-regulation of Bax," Carbohydrate Polymers, vol. 71, no. 4, pp. 509-514, 2008.

[51] G. Tan, M. Kaya, A. Tevlek, I. Sargin, and T. Baran, "Antitumor activity of chitosan from mayfly with comparison to commercially available low, medium and high molecular weight chitosans," In Vitro Cellular \& Developmental BiologyAnimal, vol. 54, no. 5, pp. 366-374, 2018.

[52] M. Zheng, B. Han, Y. Yang, and W. Liu, "Synthesis, characterization and biological safety of O-carboxymethyl chitosan used to treat Sarcoma 180 tumor," Carbohydrate Polymers, vol. 86, no. 1, pp. 231-238, 2011.

[53] Z. Jiang, B. Han, W. Liu, and Y. Peng, "Evaluation on biological compatibility of carboxymethyl chitosan as biomaterials for antitumor drug delivery," Journal of Biomaterials Applications, vol. 31, no. 7, pp. 985-994, 2017.

[54] B. Bonavida and H. Garban, "Nitric oxide-mediated sensitization of resistant tumor cells to apoptosis by chemo-immunotherapeutics," Redox Biology, vol. 6, pp. 486-494, 2015.

[55] R. Chen, "Release and activity of histone in diseases," Cell Death Disease, vol. 5, pp. 1-26, 2014.

[56] J. Wang, X.-Z. Zhao, Q. Qi, L. Tao, Q. Zhao et al., "Macranthoside B, a hederagenin saponin extracted from Lonicera macranthoides and its anti-tumor activities in vitro and in vivo," Food and Chemical Toxicology, vol. 47, no. 7, pp. 1716-1721, 2009.

[57] I. Jorgensen, M. Rayamajhi, and E. A. Miao, "Programmed cell death as a defence against infection," Nature Reviews Immunology, vol. 17, no. 3, pp. 151-164, 2017.

[58] M. Hasegawa, K. Yagi, S. Iwakawa, and M. Hirai, "Chitosan induces apoptosis via caspase-3 activation in bladder tumor cells," Japanese Journal of Cancer Research, vol. 92, no. 4, pp. 459-466, 2001.

[59] H. S. Adhikari and P. N. Yadav, "Anticancer activity of chitosan, chitosan derivatives, and their mechanism of action," International Journal of Biomaterials, vol. 2018, Article ID 2952085, 18 pages, 2018.

[60] N. Mameri, R. Salah-Tazdaï, and D. Tazdaï, Tumoricidal Effect of O-Carboxymethyl Chitin, N,O-carboxymethyl Chitosan and 2-phtalimido Chitin Evaluation with Human Tumour Cell Line, in in Proceedings of the International Conference on Chemical, Civil and Environmental Engineering (CCEE-2015), Istanbul, Turkey, June, August 2015.

[61] H. Ibrahim, E. El-Zairy, and R. Mosaad, "Preparation, characterization and median lethal dose (LD50) of carboxymethyl chitosan as target Drug Delivery," International Journal, vol. 3, no. 1, pp. 865-873, 2015. 